\title{
Alumbramiento de un código ético
}

\author{
Fernando Abellán \\ Coordinador de la Comisión de Bioética de SEFAC.
}

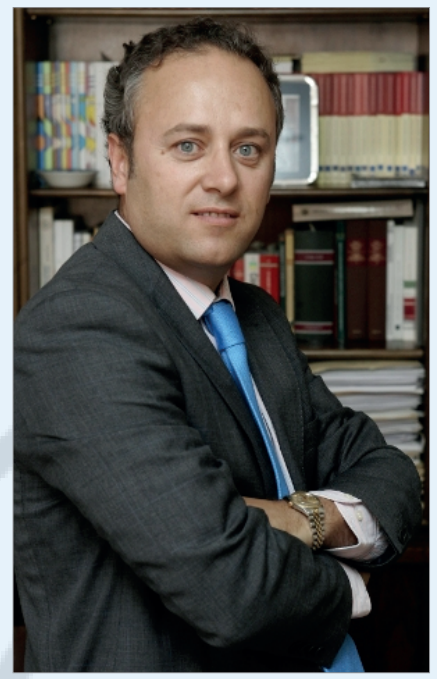

Fernando Abellán
El pasado mes de abril de 2015 nuestra Sociedad, a través de su Comisión de Bioética, concluyó el Código Ético de la Farmacia Comunitaria, objetivo ambicioso que ha ocupado el quehacer de esta comisión multidisciplinar durante los últimos dos años.

El hecho de que desde SEFAC se haya dado lugar a este texto es un acontecimiento de extraordinaria importancia, no solo por la circunstancia de que se trate del primer código ético específico de la farmacia comunitaria, sino por el compromiso que conlleva de que la excelencia presida la actuación profesional y la propia labor institucional de SEFAC. Se trata de una apuesta no solo por hacer las cosas bien desde el punto de vista técnico y científico, sino por hacerlas también de manera sobresaliente desde la perspectiva ética, incorporando valores y comportamientos que contribuyan a dignificar más la profesión y que redunden en mayores cotas de satisfacción de los pacientes en su relación con el farmacéutico.

Al mismo tiempo, que una sociedad científica con quince años de historia promueva un código ético constituye un claro signo de madurez, de consolidación como proyecto colectivo, en el que está presente su preocupación y sensibilidad por todo lo que nos rodea, desde los pacientes, pasando por el resto de profesionales sanitarios, las compañías farmacéuticas y de tecnología sanitaria, los agentes sociales y la sociedad en general.

El Código Ético de la Farmacia Comunitaria no es en absoluto un código punitivo que contenga sanciones, ni siquiera un código deontológico al modo de los que tienen los colegios profesionales, sino un código de búsqueda de la excelencia, de apuesta por una ética de máximos, de elevación de nuestro nivel de autoexigencia.
Como se advierte en la introducción, el texto se articula en cuatro grandes apartados, que abarcan la responsabilidad del farmacéutico comunitario con los pacientes y usuarios, con la sociedad, con la profesión, y la responsabilidad institucional de la propia SEFAC como organización que debe regirse por normas éticas.

Un aspecto destacable del código es que está pensado también para su aplicación en relación a la implantación de los nuevos servicios profesionales farmacéuticos (SPF), que constituyen una de las líneas estratégicas de SEFAC. Como se dice en el código, la sociedad del siglo XXI puede y debe sacar mucho más provecho del farmacéutico comunitario como agente de salud. Este último se encuentra ante el reto de hacer evolucionar su profesión hacia cotas más altas de utilidad y reconocimiento social, por lo que su interés por ampliar sus competencias más allá de sus labores tradicionales relacionadas con el medicamento debe contemplarse como algo positivo y deseable. Ahora bien, como igualmente se matiza en el código, dicha ampliación y su ejercicio responsable puede exigir en ocasiones que, desde el punto de vista ético y profesional, obtenga previamente una capacitación personal y que dicha capacitación se actualice periódicamente.

En consonancia con lo anterior, en el código se recalca que no es ético ofrecer nuevos servicios en la farmacia sin disponer, siempre que sea preciso, de una capacitación profesional que garantice estándares adecuados de calidad y seguridad para los usuarios, ni aquellos que no cuenten con el suficiente consenso científico.

Puede destacarse también en este terreno la afirmación del código relativa a que, con el fin de salvaguardar el carácter sanitario de la farmacia y de las 
competencias profesionales del farmacéutico, resulta aconsejable que dentro de aquella no se realice el comercio de bienes y servicios ajenos a los fines de la profesión y a las funciones de promoción de la salud y prevención de la enfermedad que tiene reconocidas el farmacéutico.

Por lo que se refiere a las obligaciones de los órganos de SEFAC hay que significar la proclamación de que los miembros de la Junta Directiva, Consejo de Gobierno y Delegaciones Territoriales, como representantes de SEFAC, son los primeros llamados a velar en todo momento porque se respete, cumpla y promueva el código ético. De manera más precisa, se dice que tanto al inicio de su designación, como a lo largo de la vigencia de su cargo, están obligados a manifestar cualquier tipo de conflicto de interés que pueda afectarles (vinculación con compañías farmacéuticas o de tecnología sanitaria, con las distribuidoras, participación en candidaturas a colegios profesionales, etc.).

En definitiva, SEFAC con este código se dota de una herramienta valiosa de funcionamiento para los próximos años que, al tiempo que constituye un marchamo diferencial de buen hacer respecto de otras organizaciones, pone sin duda alguna de manifiesto la fuerte responsabilidad ética que asume con los pacientes, con la profesión farmacéutica y con la sociedad.

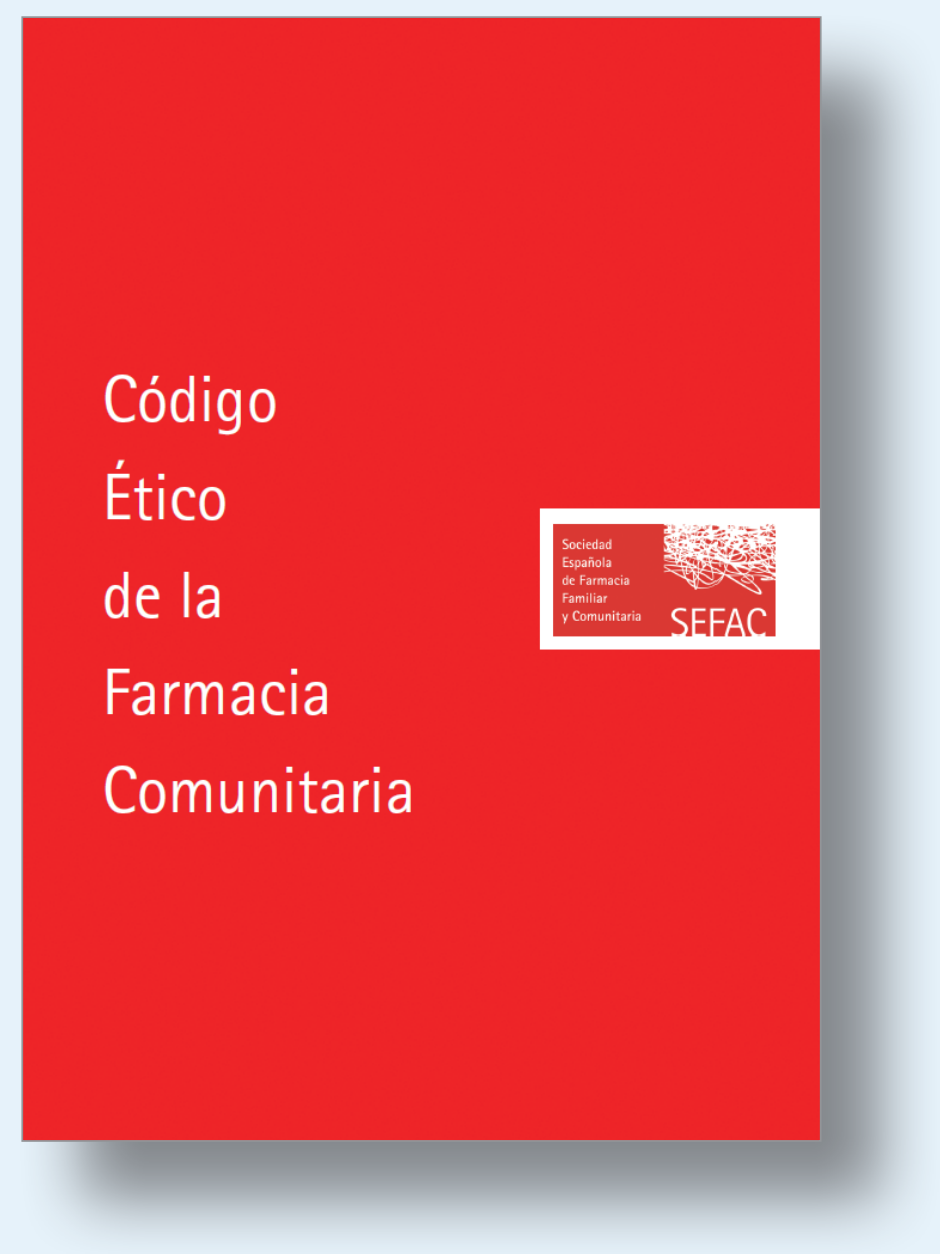

